\title{
Differential expression of immunohistochemistry markers for epithelial/squamous cells in adamantinomatous craniopharyngioma
}

\begin{abstract}
Context: Adamantinomatous cranio pharyngioma (ACP) is an epithelial neoplasm that is located in the sellar regions. It has at least four different squamous histological areas: superficial mature squamous (SMS), stellate reticulum (SR), palisaded basal columnar (PBC) cells and the wet keratin (WK).

Design: Twenty two cases of ACP were reviewed from our archives from the period 2005-2012. Immunostainings for cytokeratin 7, cytokeratin 20, cytokeratin 19. high molecular weight cytokeratin (HMWC), low molecular weight cytokeratin (LMWC), epithelial membrane antigens (EMA), cytokeraitn 5/6 and p63 were performed. In addition, immunostainings for p16, p53, Ki-67 and B-catenin were performed.

Results: HMWC was positive in all 22cases in all squamous parts. Cytokeratin 19 was positive in PBC and SR but negative in SMS and WK parts. Cytokeratin 20 was negative in all squamous parts. EMA was positive in SR and WK, but negative in PBC and SMS in 17/22 cases. p63 was positive in PBC and SR cells, but negative in WK and SMS s in 16/22cases. p16 was positive in PBC and SR in $15 / 22$ cases. Twelve cases show positive p53 immunostainings with range $2 \%-50 \%$ of the cells. Ki67 showed more than $10 \%$ positivity in 13 cases, and low positivity or negative in 12 cases. B-catenin was positive in PBC in 11 cases in cytoplasmic and nuclear pattern and was positive in 11 cases in cytoplasmic pattern only.
\end{abstract}

Conclusions: ACP has distinctive patterns of immunostainings for different epithelial and squamous markers. This knowledge helps in diagnosing ACP even in small biopsies and can help to differentiate it from its mimickers.

Keywords: craniopharyngioma, adamantinomatous subtype, immunohistochemistry, sella sella turcica

\author{
Volume 5 Issue I - 2017 \\ Noor Abu-Farsakh,' Ibrahim Sbeih, ${ }^{2}$ Hussam \\ Abu Farsakh ${ }^{3}$ \\ 'Jordan University, Jordan \\ Ilbn Hytham Hospital, Jordan \\ ${ }^{3}$ First Medical Lab, Jordan
}

Correspondence: Hussam Abu Farsakh, College of American Pathologists, Orlando Florida, USA, Email FIlab@yahoo.com

Received: August 22, 2017 | Published: October 04, 2017
Abbreviations: ACP, adamantinomatous cranio pharyngioma; PBC, palisaded basal columnar; SR, stellate reticulum; SMS, superficial mature squamous; LMWC, low molecular weight cytokeratin; HMWC, high molecular weight cytokeratin

\section{Background}

Craniopharyngioma are histologically a benign neoplasm that occurs in the sellar and suprasellar region, with an infiltrative growth pattern, accounts for $1.2-4.6 \%$ of all intracranial tumors. ${ }^{1}$ They are the most common non-neuroepithelial intracerebral neoplasm in children accounting for $5-10 \%$ of intracranial tumors in this age group. A bimodal age distribution of ACP is observed, with peaks in children aged 5-15years and adults 45-60years. ${ }^{1}$ They are often difficult to excise surgically, and they have a $10 \%$ to $40 \%$ recurrence rate. ${ }^{2}$ There are at two types of craniopharyngioma: Adamantinomatous craniopharyngioma (ACP) and papillary craniopharyngioma (PCP). Both have distinct morphology and different clinical behavior. ACP has at least four different squamous histological areas: superficial mature squamous (SMS), loosely cohesive aggregates of squamous cells known as "stellate reticulum" (SR), palisaded basal columnar (PBC) cells and nodules of wet keratin (WK) (Figure 1, Figure $2 \&$ Figure 3). Cystic cavities containing squamous debris are lined by flattened epithelium. PCP occurs virtually exclusively in adults with mean age of 40-50years. ${ }^{3,4}$ Histologically, it is different from ACP by lacking nuclear palisading, wet keratin, and dystrophic calcification. ${ }^{5}$

The tumor originates from Rathke's pouch and the craniopharyngeal duct. Metaplasia of cells derived from the tooth promordia gives rise to the ACP, while metaplastic changes derived from the buccal mucosa promordia gives rise to squamous papillary variety. ${ }^{6}$ Rathke's cleft cysts are also thought to originate from the remnants of the Rathke's pouch. Histologically, Rathke's cleft cysts are lined by a ciliated cuboidal or columnar epithelium with common squamous metaplasia. Rathke's cleft cysts are common. ${ }^{6}$ Occasionally, these cysts enlarge to become clinically detectable and cause compressive effects like craniopharyngioma. ${ }^{7-9}$ The prognosis of Rathke's cleft cysts with surgery is excellent, with a very low recurrence rate. ${ }^{7-10}$ Cytokeratins (CKs), a complex family of many different polypeptides, are expressed in epithelia and their related neoplasms. A particular epithelium can be characterized by its specific pattern among the highly diverse expression patterns of cytokeratins. ${ }^{11,12}$ In this study, we tried to do most of the squamous cell markers of Immunohistochemistry (High molecular weight HMW cytokeratin, Low molecular weight LMW cytokeratin, Cytokeratin 7, Cytokeratin 19, Cytokeratin 5/6, epithelial membrane antigen (EMA), p16 and p63. To study the various types of squamous cells and detect which layers of squamous differentiation stains with which squamous cell markers. The aim for this study is to 
facilitate detection of craniopharyngioma even if it was completely calcified or only a tiny part is available for study and confirm the diagnosis and separate it from other differentials like Rathke's cyst. Other studies ${ }^{14-16}$ have done some squamous markers, but we believe, this is the most extensive squamous markers that is present so far in the literature.

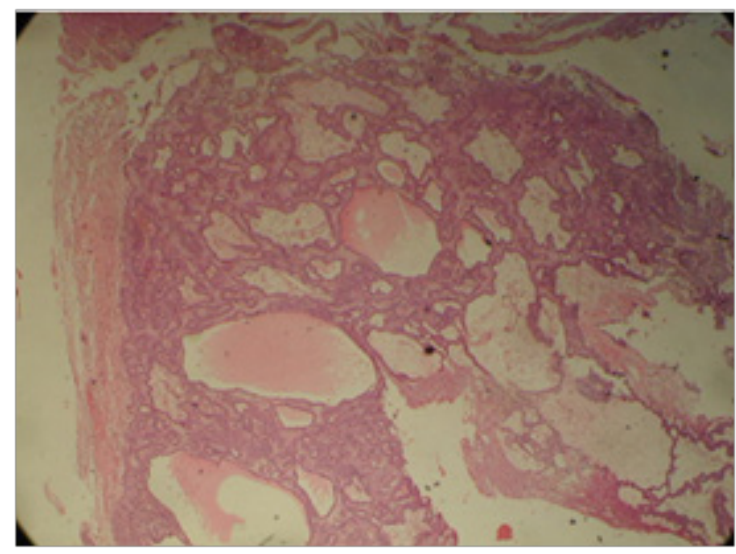

Figure I Cystic spaces within squamous cells.

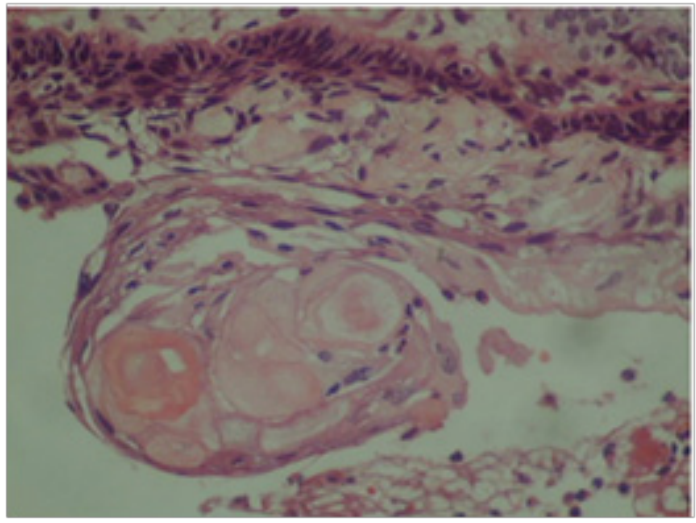

Figure 2 Wet keratin.

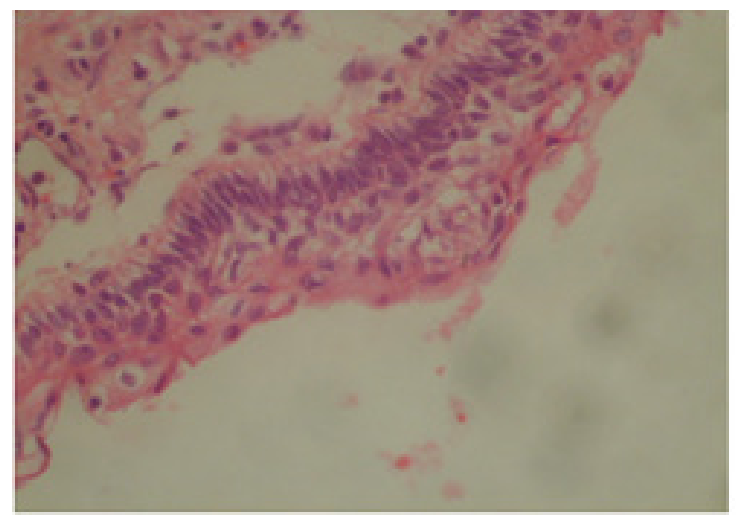

Figure 3 Basal squamous layer, stellate reticulum and superficial squamous layer.

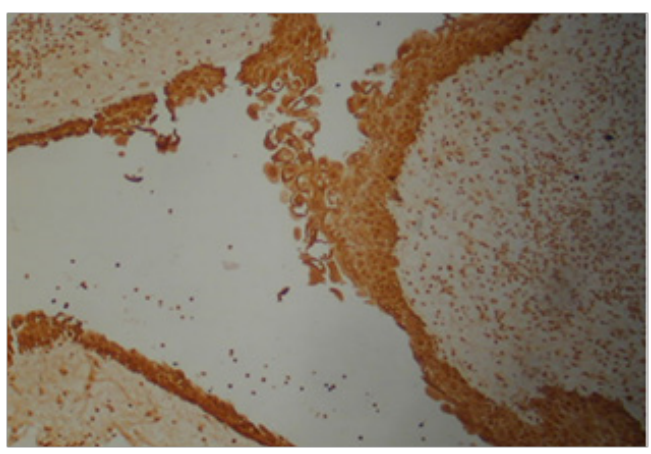

Figure 4 HMWC was positive in all 22 cases in all squamous parts.

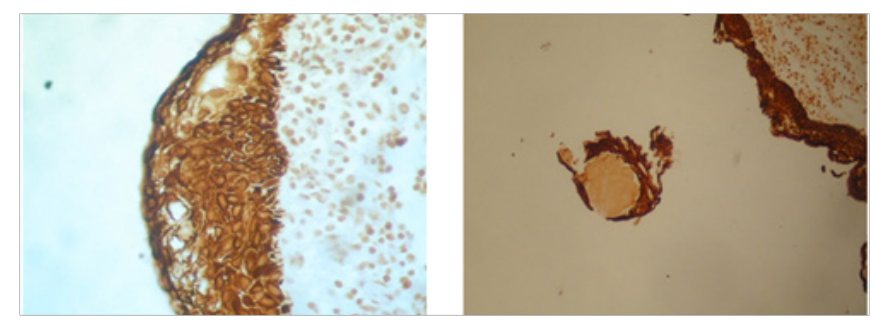

Figure 5 Cytokeratin 19 was positive in PBC \& SR but negative in SMS \& WK part.

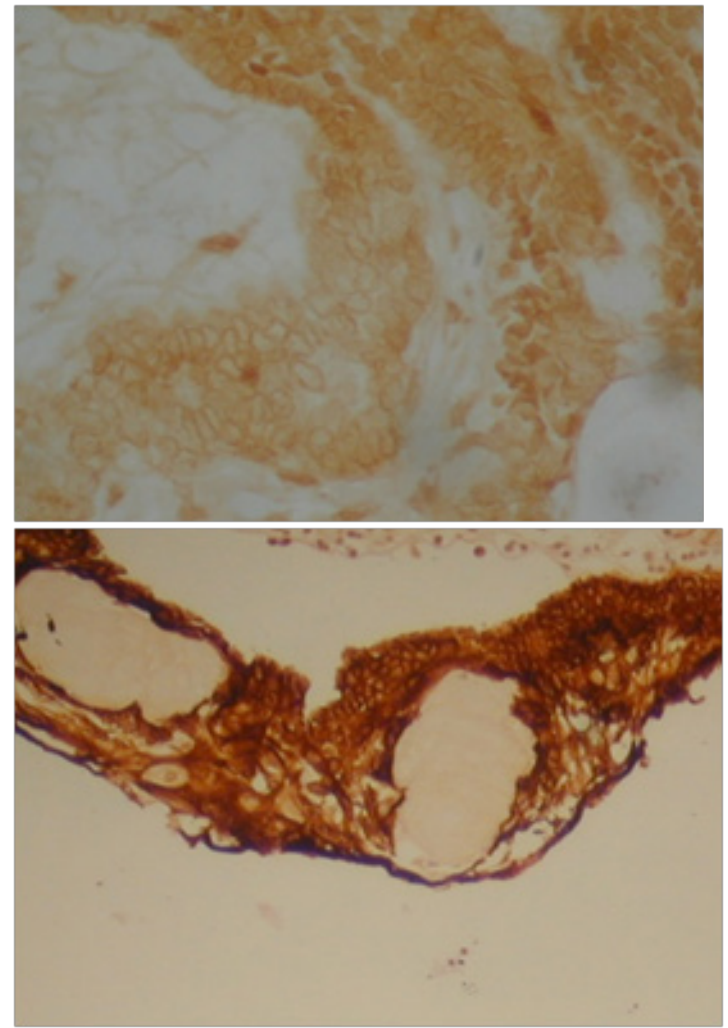

Figure 6 LMW cytokeratin: was positive in the PBCs and SMS but reduced in SR and negative in WK. 


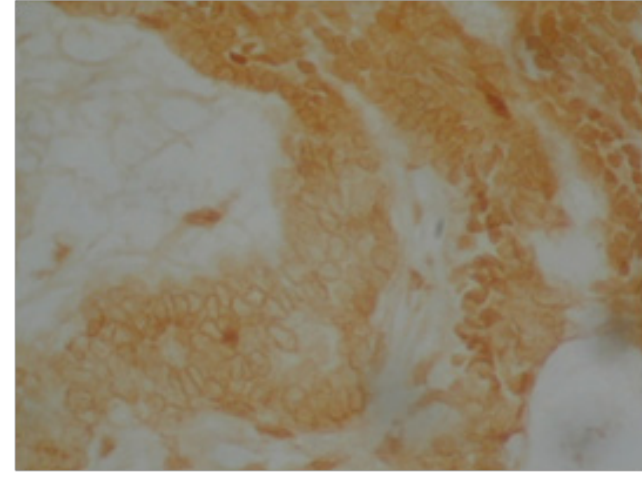

Figure 7 Cytokeratin 7 was positive in SR but not in SMS, PBC or WK cells.
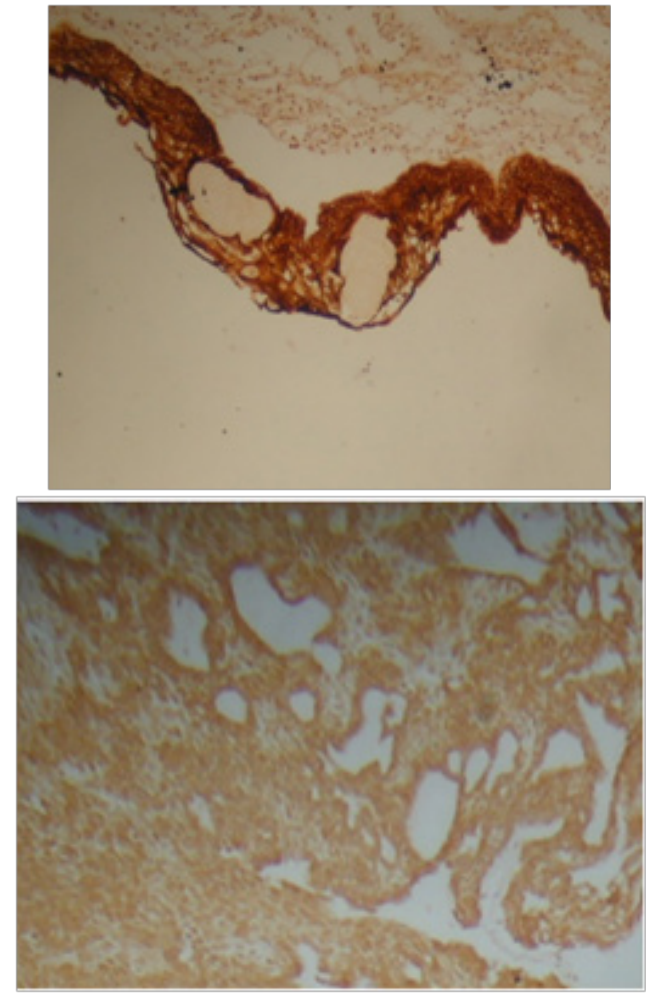

Figure 8 Cytokeratin 5/6: positive in all three layers SMS, SR and PBC but negative in wet keratin.

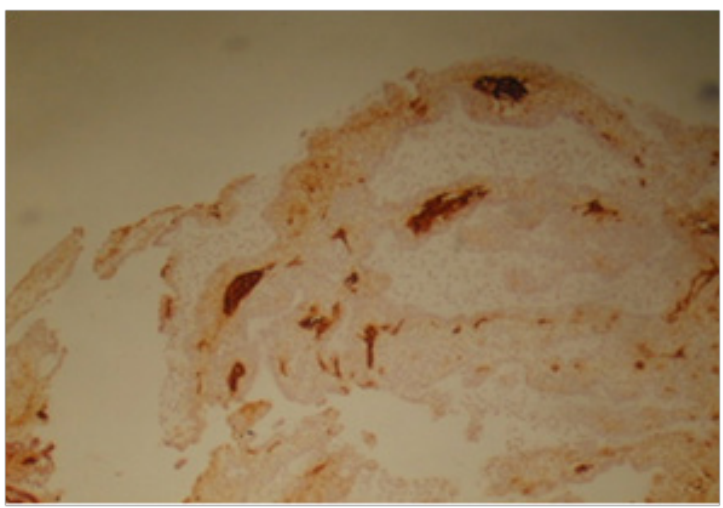

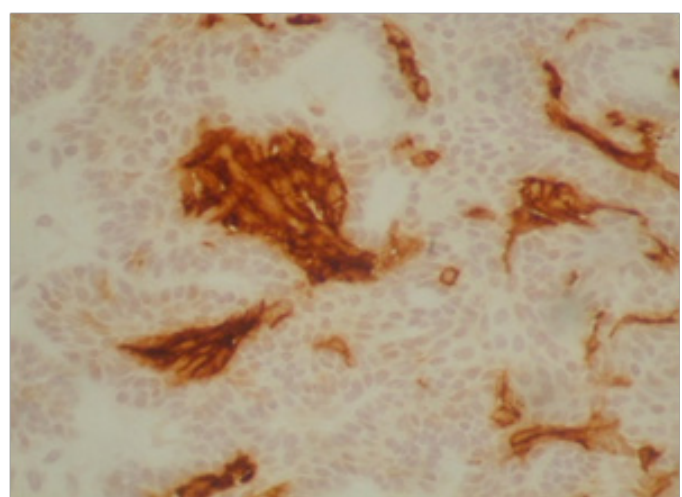

Figure 9 EMA was positive in SR and WK, but negative in PBC and SMS in $17 / 22$ cases.

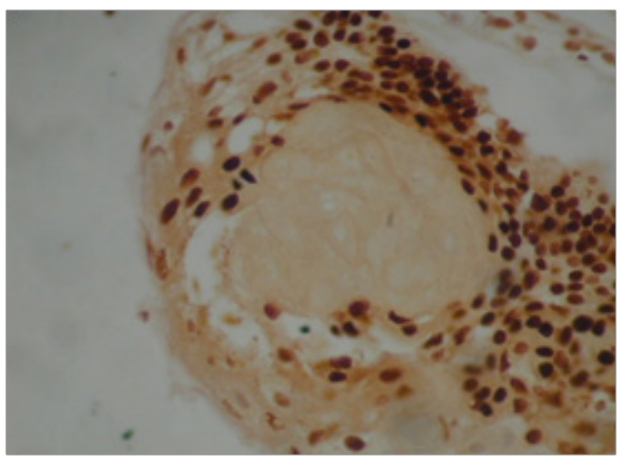

Figure 10 p63 was positive in PBC and SR cells, but negative in WK and SMS.

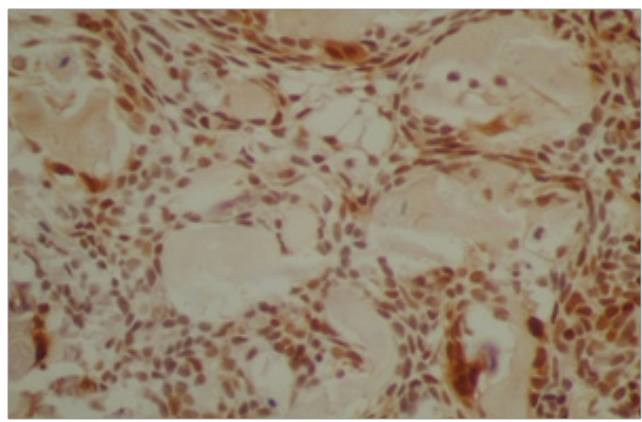

Figure I I pl6 was positive in PBC and SR in I5/22 cases.

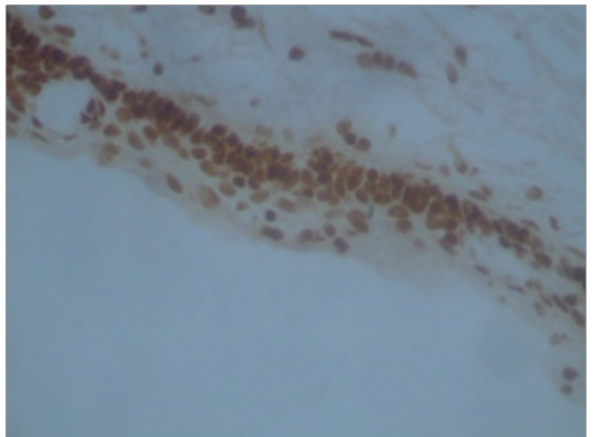

Figure 12 Positive p53 immunostainings with over $50 \%$ of the basal cells. 


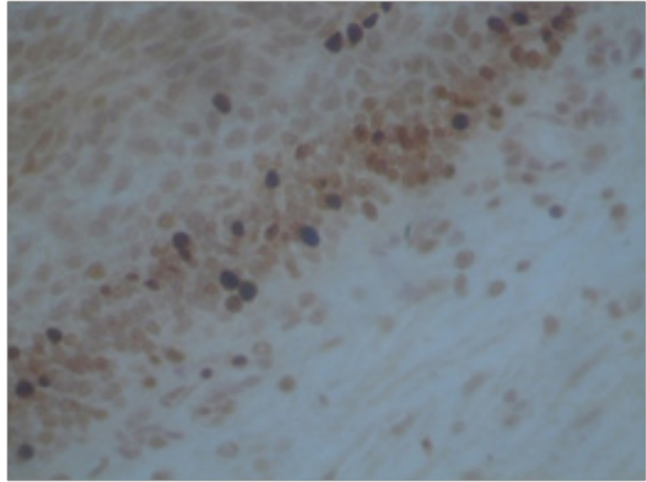

Figure $13 \mathrm{Ki67}$ showed more than 10\% positivity in I 3 cases.

\section{Material and methods}

Twenty two cases of ACP were reviewed from our archives from the period 2005-20012. Immunostainings for cytokeratin7, cytokeratin20, cytokeratin19. High molecular weight cytokeratin (HMWC), low molecular weight cytokeratin (LMWC), epithelial membrane antigens (EMA), cytokeratin 5/6 and p63 were performed. In addition, immunostainings for p16, p53, Ki-67 and B-catenin were performed.

\section{Results}

HMW cytokeratin was positive in all 22cases in all squamous parts (Figure 4). Cytokeratin 19 was positive in $\mathrm{PBC}$ and SR but negative in SMS and WK parts (Figure 5). Cytokeratin 20 was negative in all squamous parts. LMW cytokeratin: was positive in the PBCs and SMS but reduced in SR and negative in WK in 17/22 cases (Figure 6). Cytokeratin 7 was positive in the SR but not in the PBC, SMS or WK in $19 / 22$ cases (Figure 7). Cytokeraitn $5 / 6$ was positive in all three layers SMS, SR and PBC but negative in wet keratin in 22/22 cases (Figure 8). EMA was positive in SR and WK, but negative in $\mathrm{PBC}$ and SMS in 17/22cases (Figure 9). p63 was positive in PBC and SR cells, but negative in WK and SMS in 16/22 cases (Figure 10). p16 was positive in PBC and SR in 15/22 cases (Figure 11). Twelve cases show positive p53 immunostainings with range $2 \%-50 \%$ of the cells (Figure 12). Ki67 showed more than $10 \%$ positivity in 13 cases (Figure 13) and low positivity or negative in 12cases. B-catenin was positive in $\mathrm{PBC}$ in 11 cases in cytoplasmic and nuclear pattern and was positive in 11 cases in cytoplasmic pattern only.

\section{Discussion and conclusion}

Cytokeratin expression patterns identify different types of epithelial cells. Among 20 currently identified human cytokeratins, 5(CK7, CK8, CK18, CK19, and CK20) are expressed mainly in simple epithelia. CK7, CK8, and CK18 are found in trachea, urothelium of bladder, and several complex glands. CK20 is found mainly in intestinal epithelium, gastric foveolar epithelium, urothelium, and Merkel cells. ${ }^{9}{ }^{11}$ ACP has distinctive patterns of immunostainings for different epithelial and squamous markers. B-catenin immunostaining in ACP can be membranous and/or nuclear pattern, but in PCP and Rathke's cyst is exclusively membranous. Kurosaki has reported that in all cases of ACP are cytokeratin 19 positive, as in our case with similar staining pattern and intensities. ${ }^{14}$ On the other hand, cytokeratin 7 was negative in all their cases in the outer palisaded basal layer, but present in the squamous SR area. ${ }^{14}$ In out cases, Cytokeratin 20 is negative in all cases examined. Lee group reached to similar conclusions and found that cytokeratin 20 is almost never expressed in ACP; ${ }^{15}$ while they noticed strong expression in Rathke's cleft cysts. Tena-Suck found strong expression of cytokeratin 18 and 19 in ACP. ${ }^{15}$ In All studies, including ours, Cytokeratin 19 is always expressed in all layers of the ACP..$^{14,15}$

Our study highlighted extensive different squamous markers so it will be very helpful to detect the origin of any tiny tissue of craniopharyngioma and differentiate it from other squamous bearing cysts. The pattern of different cytokeratin and epithelial markers expressions helps in particular in differentiating ACP from its main mimickers: PCP and Rathke's cyst.

\section{Acknowledgements}

None.

\section{Conflict of interest}

The author declares no conflict of interest.

\section{References}

1. Bunin GR, Surawicz TS, Witman PA, et al. The descriptive epidemiology of craniopharyngioma. J Neurosurg. 1998;89(4):547-551.

2. Kolen ER, Horvai A, Perry V, et al. Congenital craniopharyngioma: a role for imaging in the prenatal diagnosis and treatment of an uncommon tumor. Fetal Diagn Ther. 2003;18(4):270-274.

3. Adamson TE, Wiestler OD, Kleihues P, et al. Correlation of clinical and pathological features in surgically treated craniopharyngiomas. $J$ Neurosurg. 1990;73(1):12-27

4. Crotty TB, Scheithauer BW, Young WF, et al. Papillary craniopharyngioma: a clinicopathological study of 48 cases. J Neurosurg. 1995;83(2):206-214.

5. Janzer RC, Burger PC, Giangaspero F, et al. Craniopharyngioma. In: Kleihues P editor. World Health Organization Classification of Tumors: Pathology and Genetics of Tumors of the Nervous System. Lyon, France: IARC Press; 2000. p. 244-246.

6. Keyaki A, Hirano A, Llena JF. Asymptomatic and symptomatic Rathke's cleft cysts. Histological study of 45 cases. Neurol Med Chir (Tokyo). 1989;29(2):88-93.

7. Asa SL. Tumors of the Pituitary Gland. Washington DC: Armed Forces Institute of Pathology; 1988. p. 167-176.

8. Steinberg GK, Koenig GH, Golden JB. Symptomatic Rathke's cleft cysts. Report of two cases. J Neurosurg. 1982;56(2):290-295.

9. Voelker JL, Campbell RL, Muller J. Clinical, radiographic, and pathological features of symptomatic Rathke's cleft cysts. J Neurosurg. 1991;74(4):535-544.

10. Sternberg SS, Antonioli DA, Carter D, et al. Diagnostic Surgical Pathology. 3rd edition. USA: Baltimore; 1999. p. 516-529.

11. Moll R, Franke WW, Schiller DL, et al. The catalog of human cytokeratins: patterns of expression in normal epithelia, tumors and cultured cells. Cell. 1982;31(1):11-24.

12. Moll R, Lowe A, Laufer J, et al. Cytokeratin 20 in human carcinomas. A new histodiagnostic marker detected by monoclonal antibodies. Am J Pathol. 1992;140(2):427-447. 
13. Kurosaki M, Saeger W, Ludecke DK. Immunohistochemical localisation of cytokeratins in craniopharyngioma. Acta Neurochir (Wien). 2001;143(2):147-51.

14. Le BH, Towfighi J, Kapadia SB, et al. Comparative immunohistochemical assessment of craniopharyngioma and related lesions. Endocr Pathol. 2007;18(1):23-30.
15. Tena-Suck ML, Salinas-Lara C, Arce-Arellano RI, et al. Clinicopathological and immunohistochemical characteristics associated to recurrence/regrowth of craniopharyngiomas. Clin Neurol Neurosurg. 2006;08(7):661-669. 